\title{
Jahrestagung 2004
}

Die Vereinigung der Deutschen Staatsrechtslehrer tagte im Jahre 2004 vom 6. bis zum 9. Oktober in der alten Universitätsstadt Jena und damit zum fünften Male nach der deutschen Wiedervereinigung in den „neuen“ Bundesländern. Sie kehrte damit an den Ort zurück, an dem vor $80 \mathrm{Jah}-$ ren, nämlich im April 1924, die erste formelle Tagung der zwei Jahre zuvor in Berlin gegründeten Vereinigung mit mehreren Referaten zu verschiedenen Gegenständen, allgemeiner Aussprache und anschließender Dokumentation in einem Tagungsband stattgefunden hatte. Hieran erinnerte auch der Dekan der Juristischen Fakultät, Prof. Dr. Hartmut Oetker, bei seiner Begrüßungsansprache am Donnerstagvormittag.

Tagungsort war im Jahre 2004 die Aula des Universitätshauptgebäudes am Fürstengraben, die durch das von Ferdinand Hodler zu Beginn des 20. Jahrhunderts geschaffene monumentale Wandbild („Auszug deutscher Studenten in den Freiheitskrieg von 1813“) in besonders eindrucksvoller Weise geschmückt und geprägt wird. An der Tagung nahmen mehr als 300 Mitglieder teil, des weiteren mehr als 150 Begleitpersonen und Gäste, unter ihnen auch zahlreiche ausländische Kollegen.

Bei der Mitgliederversammlung am Mittwochnachmittag gedachte die Vereinigung ihrer seit der letzten Tagung verstorbenen Mitglieder Christoph Trzaskalik, Hans Marti und Albert Bleckmann, denen sie stets ein ehrendes Andenken bewahren wird. Der Vorsitzende konnte mehr als 40 neue Mitglieder begrüßen, die sich der Versammlung kurz vorstellten. Mittlerweile zählt die Vereinigung mehr als 600 Mitglieder.

Das wissenschaftliche Programm stand unter dem Gesamtthema „Der Sozialstaat in Deutschland und Europa“. Insgesamt acht Berichte zu den vier Einzelthemen griffen zentrale Aspekte verfassungs- wie verwaltungsrechtlicher Art auf und fanden ein durchweg lebhaftes Echo in der Aussprache, die der vorliegende Band neben den Vorträgen selbst wiedergibt.

Eingerahmt wurden die Berichte und Diskussionen durch abendliche Empfänge. Am Mittwochabend hießen der Rektor der Friedrich-SchillerUniversität Jena, Herr Prof. Dr. Klaus Dicke, sowie der Oberbürgermeister der Stadt Jena, Herr Dr. habil. Peter Röhlinger, die Teilnehmer in der Campus-Mensa der Universität willkommen. Der Empfang der thüringischen Landesregierung am folgenden Abend fand nicht in Jena, sondern im geschichtsträchtigen Gebäude des Weimarer Nationaltheaters statt, 
Tagungsort der Weimarer Nationalversammlung im Jahre 1919. Dort wurde die Vereinigung vom Justizminister des Freistaats, Herrn Harald Schliemann, begrüßt. Im Anschluß genoß man gemeinsam Giacomo Puccinis Einakter „Gianni Schicchi“.

Der traditionelle Samstagsausflug führte nach Erfurt, wo bei herrlichem Wetter Dom und Severi-Kirche sowie weitere Sehenswürdigkeiten der eindrucksvoll restaurierten Altstadt besichtigt wurden.

Ein besonders herzlicher Dank gilt den Kolleginnen und Kollegen aus Jena für die außergewöhnlich zeitintensive Vorbereitung und perfekte Durchführung der Tagung, allen voran Frau Prof. Dr. Martina Haedrich, die als kooptiertes Vorstandsmitglied die Hauptlast zu tragen hatte. Dankbar vermerkt wurde auch der Einsatz der Ehegatten bei den verschiedenen Punkten des Begleitprogramms, das sich mit seinen Führungen und Exkursionen regen Zuspruchs und großen Beifalls erfreute. Die Tagung fand insgesamt in einer zugleich entspannten wie konzentrierten Atmosphäre statt, in der - wie schon in seinem Tagungsbericht 1924 Fritz Stier-Somlo vermerkt hatte - „an die Arbeit zu gehen eine Freude war“. 